\title{
DIABESITY: WERE WE ARE WRONG AND WHAT IS THE COST?
}

\section{Chelaru Sorina-Alina1, Gatrinoiu Doina1, Ion lleana1}

${ }^{1}$ Faculty of Medicine, University „Ovidius” of Constanţa

Sorina-Alina Chelaru

\section{ABSTRACT}

Obesity, metabolic syndrome, prediabetes and dislipidemia are the major risk factors for developing type 2 diabetes and posible severe complications which can decrese quality of life and increase population mortality.

Due to its epidemic characteristic and high costs of care, diabetes became a major health problem around the world.

It is compulsory to know epidemiological data and possible evolution of diabetes to ensure rational health policies among risk population.

Keywords: diabetes, obesity, globalization

\section{Introduction}

Diabetes mellitus is a disease mentioned since ancient times and many discoveries made over time have led nowadays to a continous scientific progress based on clinical and therapeutical conduct targeting physiopathological mechanism (1).

The Ebers papyrus from 1559 B.C is the first written proof that mentions diabetes symptomatology by describing polyuria (2).

The literature data highlights an impressive dynamics of the increasing prevalence of the disease. Etu Seppala said that , diabetes mellitus exists to all nations, to all society levels, to the poor and the rich, to blacks and whites, to the highly educated and uneducated, to religious and atheists, to famous politicians and unknown people, without shelter" (3).

In reality, statistical data exceeds those from literature claiming that for each diabetic patient there is one more undiagnosed. In 2017, International Diabetes Federation declared 425 milion people with diabetes and a $48 \%$ estimated increase for 2045 (4).

The dramatic increase in number of cases with type 2 diabetes was considered a consequence of the high number in obesity prevalence leading to the use of new terms as „Diabesity” to emphasize the association 
between this two diseases.

Thus, the reality of 21 st century is governed by obesity being the main health disorder and major risk for type 2 diabetes (3). It is responsible for $80 \%$ of the cases with diabetes, $35 \%$ with ischemic cardiopathy and $55 \%$ with arterial hypertension (5).

All the increases lead to globalization phenomenon of diabetes with major impact on the costs of disease management and associated complications.

\section{Type 2 Diabetes Mellitus}

Is a chronic disease defined by chronic hyperglycaemia due to a relative insulin deficiency and associated insulinresistance. Secondary, it occur metabolism disorders of carbohydrates, proteins and lipids with major impact on the energy metabolism (1).

Over time, studies have shown that the clinical syndrome associated with insulinresistance and compensatory hyperinsulinemia are prediabetes, metabolic syndrome, obesity, dyslipidemia, primary arterial hypertension, aterosclerosis, polycystic ovary syndrome, non-alcoholic hepatic steatosis, sleep apnea syndrome and different types of cancers ( colon, endometrium, pancreas, renal). It has also been identified to first degree relatives of type 2 diabetes patients $(6,7,8)$.

According to UKPDS, insulin secretion deficiency precedes with 10 years the clinical onset of type 2 diabetes explainig why micro and macrovasculare complications are already present at $50 \%$ of patients (9).

Prediabetes represent and intermediate stage between normal glucose tolerance and diabetes. Also, the cardiovascular risk associated with diabetes has been sustained by many studies by demonstrating that progressive relation between hyperglycaemia and the disease starts at values far below cutt-off point. Another study has shown that the risk for acute myocardial infarction and cerebral stroke increases 15 years before diabetes diagnosis (10).

So, type 2 diabetes has become a cardiovascular disease due to micro and macroangiopathic disorders.
Obesity

In 2000, World Health Organization stated that is the first time in human history when obesity and overweight replaces the major health problems of the past century (11) as malnutrition or infectious disease and in 2002 said that, Obesity is the one of the most obvious but neglected public health problem" $(12,13)$.

So, at the end of 20 th century, $60 \%$ of the american population was overweight and $26 \%$ obese (14).

Furthermore, the studies have revealed that obese adults represents a real risk for their own children. So, the child of an overweight adult has $40 \%$ risk to become also overweight and the number doubles in the case of both parents being a tipical example transfer risk for future generation $(11,15)$.

More worrying is the fact that the global prevalence of child and yought overweight is $10 \%, 2 \%$ of them being obese (15).

The assumptions for 2020 are dark placing overweight to $77.6 \%$ and obesity to $40.2 \%$ for men and to $71.1 \%$ and $43.3 \%$ for female.

Along with increased prevalence figures, morbidity and mortality has reached alarming levels. Annually, in Europe, at least one death of 13 it is related to overweight. $(16,17)$. So, obesity has become among the first causes of mortality that can be prevented (18).

There are many causes of this real pandemics and a major role has been played by environmental changes after 2nd World War on the background of individual genetic predisposition. Urbanization, modernization and industrialization were directly involved in obesity expansion and economic progress and rapid technology have led to a major decrease in daily physical activity (19).

Various studies have shown differences between members of the same ethnic group who lived in different environments proving that prevalence increases with migration to less traditional lifestyle (18). They also added a major change in diet by promoting food with high amount of lipids and simple carbohydrates (5).

For the last 200 years, it has been also a major change in the percentage of consumed 
food principles, increasing from $10 \%$ to $13 \%$ for proteins and from 25 to $40 \%$ for lipids (21).

We known that overweight occurs in the context of under-energy consumption. The data shows that the number of ,fast food" restaurants has tripled compared to 1972 and for each $10 \%$, the number of obese people has increased with 9\%. An American study revealed that only 38\% of the food was eaten at home and the same percent never cooked a meal by using basic food (22).

Thus, the food consumption has been increased 18 times in comparison with 1970 because of eating outside healthy family environment from the perspective of self control caloric intake. (23).

A medium fast food portion has a caloric intake between 1000-2000 calories, the size increasing continously. The classical hamburger has become 6 times biger in 2003 compared to 1957, the caloric intake significantely increased from 210 to $680 \mathrm{kcal}$. A daily caloric ratio of a person with medium physical activity is provided by 3-4 hamburgers but it is important to mention that besides this there were consumed fries, beverages with high amount of sugar and dessert.

So, the considerable overdose of the daily calorific demand determines storage in adipose tissue and newly or increase of overweight $(22,23)$.

Worrying is that $70 \%$ of the children between 6 and 8 year old prefers fast food and they think that is healthier. The average excess of at least $200 \mathrm{kcal}$ per day leads to early obesity. Alarming is that children consume at school around $10-15 \%$ of calories from machines (23).

If in 1970, the caloric intake in USA was $3250 \mathrm{kcal} / \mathrm{zi}$, in 1998 it reached $3800 \mathrm{kcal} /$ day and the consumption of sugar increased to $20 \%$. All of this has been amplified by a variety of prepared and semi-prepared meals prefered by the majority of the families because it low price and lack of time for cooking at home. On a daily basis, $40 \%$ of the americans ar eating at the restaurants (24).

Despite all this, the lack of movement is a cornerstone in creating the obesogenic environment. Once we had television, it has been an increase of obesity prevalence about $6 \%$ for each hour of viewing. A study from 2010, has shown that the time used for watching TV increases the general, cardiovascular and through cancer mortality risk. Global risk approach revealed that $80 \%$ of total deaths are due to cardiovascular diseases in case of those who spent more then 4 hours in front of the television $(23,24)$.

Also, walking has been replaced by car and each hour in it increses the risk of obesity y $6 \%$. On the other hand, each kilometer walked daily decreases the probability ofobesity with 5\% (23).

Worrying is also the association between diabetes and pregnancy more and more often with major risk of perinatal morbidity and mortality (34). A possible increase in incidence coukd be because of the high number of overweight and obese moms and with the age $>35$ year old (2).

To all these, the role of the mass media is decisive conclusive by using daily obese messages (19).

In the same time, americans are spending 100 billions dolars on fast food restaurant in comparison with 6 bilions in 1970 (25).

In 2002, USA declared costs for diabetes about 132 bilion dolars. Afterwards, in 2007, the costs increased to 174 bilion dolars with an estimate for 2020 of 192 bilion dolars.

However, the 2012 assessments showed an increase in diabetes costs to 245 billion dolars, of which 176 billion (72\%) were direct costs and 69 billion (28\%) indirect costs. Direct costs were related to antidiabetic treatment (12\%), treatment of complications (18\%), hospitalizations (43\%) and nursing services $(8 \%)$. Indirect costs resulted from an increase in absenteeism (5 trillion) and declining work capacity (20.8 trillion), incapacity to work due to disease disabilities (21.6 trillion), and decreased productivity by increasing mortality (18.5 trillion) (26).

In 2015, diabetes-related health expenditures exceeded expectations by far at a rate of $12 \%$, or 673 billion dolasglobally (22).

To all this is added the costs allocated to obesity and associated diseases quantifying 7\% of the health budget (25).

\section{Conclusions}

Knowing epidemiology data and evolutionary trends of diabetes is necessary to 
ensure rational health policies for the population at high risk of developing this disease (1).

In this context, preventive measures are urgently required and the objective of a quantifiable risk factor would be essential in this initiative.

\section{References}

1. Şerban V., Tratat român de boli metabolice 1, Brumar, Timişoara, 2010;

2. Bilous R., Donnelly R., Handbook of diabetes 4th edition, Wiley-Blackwell, 2010;

3. Etu-Seppala L.: Long Way but real hope. Diabetes Voice, 2001, 46:5.

4. https://diabetesatlas.org/;

5. Graur M., Obezitatea, Junimea, Iaşi, 2004;

6. Bornfeldt K., Tabas I.Insulin Resistance, Hyperglycemia and Atherosclerosis. Cell Metab. 2011 Nov 2: 14 (5): 575-585;

7. Wilcox G. Insulin and Insulin Resistance. Clin Biochem Rev Vol 26 May 2005:19-39;

8. Uduals Zhou et al. Link between insulin resistance and hypertension: what is the evidence from evolutionary biology? Diabetology\&Metabolic Syndrome 2014, 6:12;

9. UK Prospective Diabetes Study Group. UK prospective diabetes study 16 . Overview of 6 years' therapy of type II diabetes: a progressive disease. Diabetes 1995;44:124958

10. Coutinho M., Gerstein H.C., Wang Y., Yusuf S. The relationship between glucose and incident cardiovascularnevents. A meta regression analysis of published data from 20 studies of 95.783 individuals followed for 12.4 years. Diabetes Care 1999; 22: 233-41.

11. Members of the management taskforce of the EASO. Management of obesity in adults: project for european primary care. Int J Obes Relat Metab Disord 2004: 28:S226-S31

12. World Health Organization, Food and Agriculture Organization of the United Nations. Diet, Nutrition and the prevention og chronic diseases. Report of a joint WHO/ FAO expert consultation (WHO Technical Report Series 916). Geneva:2003

13. James PT, Rigby N, Leach R; International Obesity Task Force. The obesity epidemic, metabolic syndromeand future prevention strategies. Eur J Cardiovasc Prev Rehabil 2004; 11:3-8

14. Mark H., RobertbS. Porter, Manualul Merck de diagnostic şi tratament ediţia a XVIII-a, ALL, 2009

15. Wallis C. The obesity warriors.Time 2004;163:96-104

16. Nguyen D., The epidemiology of obesity. GastroenterolClinNorthAm 2010;39((1):):17

17. Banegas J.R, Lopez-Garcia E., GutierezFisac J.L et.al. A simple estimate of mortality attributable to excess weight in the European Union. Eur J Clin Nutr 2003:57(2):201-8

18. Campos P., Saguay A., Ernberger P. Et.al. The epidemiology of overweight and obesity: public health crisis or moral panic? Int Epidemiol. 2006;35(1):55-60

19. Hâncu N. Diabetul zaharat, nutriţia şi bolile metabolice vol.2 , Echinox, Cluj Napoca, 2010

20. Hodge A.M., Zimmet Z.P.The epidemiology of obesity.Clin Endocrinol Metab 1994;8(3):577-591

21. Mincu I, Mogoș V. Bazele practice ale nutriţiei omului bolnav, RAI, Bucureşti, 1997

22. Chopra M., Galbraith S. A global response to a global problem: the epidemic of the overnutrition. Bulletin of the World Health Organization 2002;80:952-958

23. Mogoş V.T, Dondoi C., Terapia nutriţională a excesului ponderal, Enciclopedică, Bucureşti, 2011

24. Dunstan D.W., Barr Elm, Healy G.N. et al., Television viewing time and mortality. The Australian Diabetes, Obesity and Lifestyle Study. Circulation 2010;121:384-91.

25. Moshe H., Yariv Y., Goals of Metabolic management of gestaional diabetes: is it all about the sugar?, Diabetes Care, 2007,30, supl.2, S251

26. Conway b., Rene A., Obesity as a disease: no lightweight matter. Obesity Rev 2004;5:14551

27. Frank B., Globalization of diabetes, Diabetes cae 34:1249-1257,2011 